Document downloaded from:

http://hdl.handle.net/10251/79894

This paper must be cited as:

Martín Gorriz, B.; Torregrosa, A.; García Brunton, J. (2011). Feasibility of peach bloom thinning with hand-held mechanical devices. Scientia Horticulturae. 129(1):91-97. doi:10.1016/j.scienta.2011.03.012.

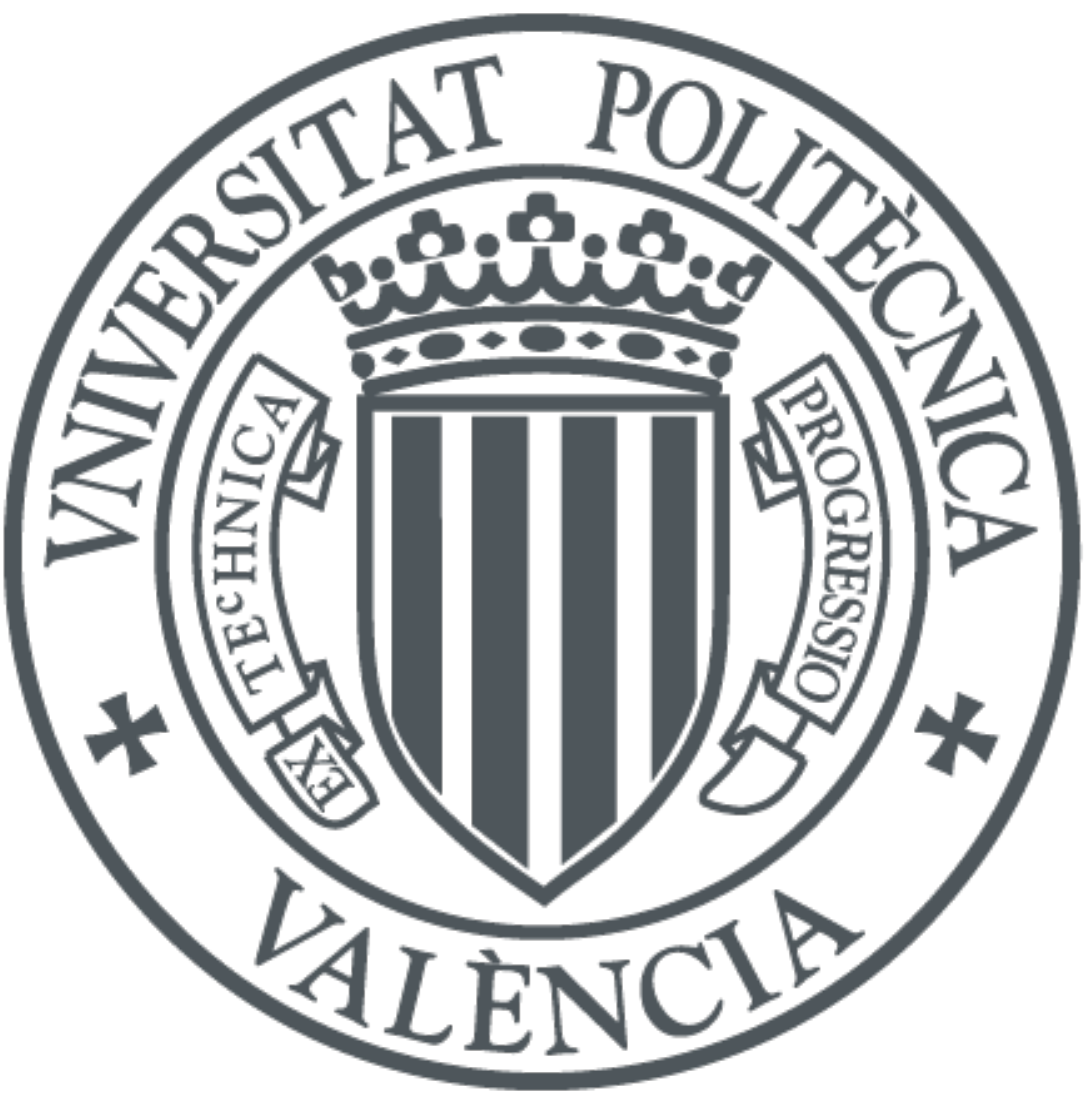

The final publication is available at

http://doi.org/10.1016/j.scienta.2011.03.012

Copyright Elsevier

Additional Information 


\section{Feasibility of peach bloom thinning with hand-held mechanical devices}

2 B. Martin-Gorriz ${ }^{1}$, A. Torregrosa ${ }^{2}$, J. García Brunton $^{3}$

$3 \quad{ }^{1}$ Universidad Politécnica de Cartagena. Dpto Ingeniería Alimentos y Equipamiento

4 Agrícola. Paseo Alfonso XIII, nº 48. 30203 Cartagena (Spain). E-Mail:

5 b.martin@upct.es

$6 \quad{ }^{2}$ Universitat Politècnica de València. Dpto Ingeniería Rural y Agroalimentaria. Valencia 7 (Spain).

$8 \quad{ }^{3}$ Instituto Murciano de Investigación y Desarrollo Agrario y Alimentario. Murcia

9 (Spain).

11 Abstract:

12 The use of hand-held mechanical devices to thin blooms of peach trees trained into the

13 "free Italian vase" form was studied. Three devices were tested, and no differences were

14 found among them in terms of thinning time and number of fruits per $\mathrm{cm}^{2}$ of trunk 15 cross-sectional area (TCSA) at harvesting. Thinning, by hand or mechanically, reduced 16 the yield per tree by $26 \%$ to $33 \%$ with respect to not thinning; however, thinning 17 increased the fruit size. In both years, the yields of fruit $>67 \mathrm{~mm}$ in the thinned trees ranged from 40.4 to $53.4 \mathrm{~kg}$ tree $^{-1}$, respectively, whereas in the un-thinned trees, it was 25.1 and $18.2 \mathrm{~kg}$ tree $^{-1}$ in 2009 and 2010, respectively. Hand thinning took $385 \mathrm{~h} \mathrm{ha}^{-1}$, and mechanical thinning reduced this time by $89 \%$. The cost of hand thinning was $4.8 €$ tree $^{-1}$, whereas the cost of mechanical thinning ranged from 0.4 to $1.1 €$ tree $^{-1}$. The economic study showed that the total yield value was similar with hand and mechanical thinning, but the cost of mechanical thinning was only $10-18 \%$ that of hand thinning.

Keywords: Mechanical thinning; Branch brusher; Peach; Fruit; Harvest; Prunus Persica; Hand-held thinners.

\section{Introduction}

29 The plentiful blooms of peach trees produce an excessive number of small fruits with 30 low market value. The usual way to reduce the excess of flowers or green fruits is to thin them by hand. In Murcia (Spain), farmers try to leave fruits 8-10 $\mathrm{cm}$ apart on the tree, allowing the fruit to get to a marketable size. Thinning is done from bloom until 40-60 days after full bloom (DAFB) (Costa and Vizzotto, 2000). In early cultivars and

34 in those destined for the fresh market, the most appropriate time to thin is at the bloom 
60

appearance to obtain the full development of the fruit. Bloom thinning reduces the early competition between fruits and usually increases fruit size. Byers and Lyons (1985), report increases of 20 to $30 \%$ in fruit size thinning at bloom in comparison with thinning 40 to 50 DAFB. However, in places with frost risks, thinning is done when the risk is over, and by then, the fruits are usually developed. In any case, thinning must be done before the hardening of the fruit stone.

Some researchers recommend eliminating 50-60\% of the flowers by mechanical thinning (Schupp et al., 2008), just as in hand thinning (Myers et al., 2002). The optimum level of crop load, which is usually expressed as the number of fruits per unit of branch length or the number of fruits per trunk cross-sectional area (TCSA), differs for each cultivar and may also change slightly for the same cultivar when grown at different sites (Miranda and Royo, 2003).

The economic profit obtained with thinning is due to the higher price that the bigger fruits usually get, but this higher price must compensate for the total yield reduction of the tree. It is necessary to reach the optimum point between size increase and yield reduction that achieves the maximum net value of the crop (Myers et al., 2002). That optimum point depends on cultural practices as well as biological, environmental, and economical factors, particularly the cultivar, time of thinning, fruit size at the time of thinning, tree nutrition, economic value of different sized fruit and cost of labour. Scott and Rasmussem (1990) developed a mathematical model to optimize the thinning intensity in peaches using easily measurable parameters. Mathematical models are useful tools for optimizing thinning, but the parameters must be obtained for any particular agricultural situation.

In Murcia (Spain), the three most labour-consuming tasks in peach cultivation are pruning, thinning and harvesting, which represent $22 \%, 32 \%$ and $45 \%$ of the total time, respectively (Garcia, 2007; Torregrosa et al., 2008). At present, thinning is done by hand. The time required to thin a tree depends on its size, the amount of fruit to be thinned and, above all, the final use of the peaches (fresh market or industry). The time required for hand thinning ranges from $302 \mathrm{~h} \mathrm{ha}^{-1}$ to $444 \mathrm{~h} \mathrm{ha}^{-1}$ for peach and nectarine trees (Garcia, 2007). 
The commercial mechanical tractor-driven thinning equipment already existing requires hedge-trained trees (Baugher et al., 2010; Schupp et al., 2008), but in Murcia, the most common training system is the "free Italian vase", where that equipment cannot work appropriately. Thus, hand-held devices were chosen because they can be used in any training system (Martin et al., 2010).

Mechanical thinning devices usually reduce the thinning time but are not able to keep a high uniformity of distances between fruits (Martin et al., 2010; Rosa et al., 2008; Schupp et al., 2008). However, some researchers have demonstrated that it is possible to obtain peaches of marketable sizes without a uniform separation between fruits. According to Marini and Sowers (1994), if peaches are thinned non-uniformly throughout the canopy, the lack of thinning individual shoots will be partially compensated by the adequate thinning of most of the tree. Miranda and Royo (2002) concluded that fruit distribution on the shoot had little or no influence over either final diameter or yield.

As hand thinning is an intensive task that must be done within a short period of time by trained workers at a high economic cost, the objective of this study was to determine if hand-held mechanical devices used at bloom are an alternative to traditional hand thinning in "free Italian vase" peach trees. The parameters for analysis were thinning time, crop load, fruit size and economic value of marketable fruit for the fresh market.

\section{Materials and Methods}

\subsection{Treatments}

The research was conducted in 2009 and 2010 on a peach (Prunus persica L. Batsch, cv Carson) orchard located in Caravaca (Murcia, Spain). The trees were 8 years old and planted in a frame with $5 \mathrm{~m}$ between rows and $3 \mathrm{~m}$ spacing within rows. The trees measured $3 \mathrm{~m}$ in diameter and were $3.5 \mathrm{~m}$ tall. The average trunk height was $0.60 \mathrm{~m}$, and the average trunk diameter was $0.14 \mathrm{~m}$. The main branches were 1.7-2.1 $\mathrm{m}$ long and formed $140-160^{\circ}$ angles with the trunk. The secondary branches were $0.8-1.3 \mathrm{~m}$ long and formed $80-120^{\circ}$ angles with the trunk. The trees were trained to a "free Italian vase" shape and were hand-pruned.

The following treatments were used: 
1. Hand thinning: the treatment control. The thinning was done by workers who eliminated green fruits from all the branches on the tree (with or without ladders), leaving one fruit approximately every $10 \mathrm{~cm}$, which is adequate to thin peaches for the fresh market.

2. Device A: electric hand-held fruit remover (Volpi, Davide e Luigi Volpi S.p.A. Casalromano, Italy). This device was $2.5 \mathrm{~m}$ long and weighed $2 \mathrm{~kg}$. It had a head with six rotating fingers (Fig. 1) and was powered by a $12 \mathrm{~V}$ electric motor that operated at two fixed speeds, 714 and $833 \mathrm{rev} \mathrm{min}^{-1}$. After preliminary tests, $714 \mathrm{rev} \mathrm{min}^{-1}$ was determined to be the most suitable speed for thinning. Electricity was supplied by a 12 V, 75 Ah car battery, which remained on the ground, and a 15-m long electric extension cord.

3. Device B: electric hand-held fruit thinner prototype (Spanish patent, ES20091448). This thinner had a rotating cylinder with 10 flexible cords, placed at the top of a pole $2 \mathrm{~m}$ in length (Fig. 2). A $12 \mathrm{~V} \mathrm{DC}$ motor, $0.12 \mathrm{~kW}$, moved the cylinder. Although the speed was variable, it was set to $250 \mathrm{rev} \mathrm{min}^{-1}$. Electricity was supplied by a $12 \mathrm{~V}, 75$ Ah car battery, which remained on the ground, and a $15 \mathrm{~m}$ long electric extension cord.

4. Device C: electric hand-held flower thinner (Electrocoup. Infaco S.A. Cahuzac sur Vere, France). This device was $2.0 \mathrm{~m}$ long and weighed $2 \mathrm{~kg}$. It had a rotary head with a four-finger comb that operated at $770 \mathrm{rev} \mathrm{min}^{-1}$ (Fig. 3). Powered by a $48 \mathrm{~V}$ electric motor, it was equipped with a portable battery bag, which facilitated worker mobility in the field.

5. Un-thinned: this treatment was used as a reference to determine the number and size of fruits produced by un-thinned trees and also to measure the thinning intensity.

The experiment was designed as a randomised block, divided into 5 plots; each plot had 3 trees (replicates) in 2009 and 6 trees in 2010.

\subsection{Data collection}

In 2009, the flowers were thinned on March 21, 6 DAFB with devices A, B and C. The green fruits were thinned by hand (control) on May 7, 62 DAFB. In 2010, the flowers were thinned on March 26 (6 DAFB), and the green fruits were thinned on May 11 (53 
136 DAFB). The hand thinning was done, both years, on the same dates as the whole 137 commercial orchard.

139 Each year, the fruit was harvested on three dates. In 2009, it was harvested at 130, 136 140 and 140 DAFB (July 14th, 20th and 24th); in 2010, it was harvested at 125, 130 and 134

141 DAFB (July 21st, 26th and 30th). Only firm, ripe fruits (based on the ground colour)

142 were harvested on the first two dates, and all the remaining fruits were harvested on the 143 last date.

145 On the first thinning day of 2009 and 2010, the trunk diameter of each tree was

146 measured at $30 \mathrm{~cm}$ above the ground to calculate the TCSA. In 2010, the thinning

147 intensity was determined by measuring on each tree the length of two scaffolds and the

148 distance between flowers before and after each thinning treatment.

150 On each harvest date, several parameters were analysed: (i) the fruit harvested from each tree was weighed using an electronic balance with a resolution of $50 \mathrm{~g}$ to determine the yield per tree $\left(\mathrm{kg} \mathrm{tree}^{-1}\right)$ and yield efficiency $\left(\mathrm{kg} \mathrm{cm}^{-2} \mathrm{TCSA}\right)$, (ii) the number of fruits per tree (no. fruit tree ${ }^{-1}$ ) was counted, and the fruit load (no. fruit $\mathrm{cm}^{-2}$

154 TCSA) was calculated, (iii) the fruit mass ( $\mathrm{g}$ fruit $^{-1}$ ) was obtained indirectly by dividing 155 the yield per tree by the number of fruits, (iv) the fruit size category (\% no. fruit tree ${ }^{-1}$

156 and $\mathrm{kg} \mathrm{tree}^{-1}$ ) was obtained from a sample of 150 fruits per tree. It was measured using 157 electronic calliper with $0.1 \mathrm{~mm}$ resolution. The collected fruits were divided into four 158 categories based on their diameters: first category, fruits over $67 \mathrm{~mm}$; second category, 159 fruits 61-67 mm; third category, fruits 56-61 mm; and fourth category, fruits under 56 $160 \mathrm{~mm}$.

162 Thinning operations were recorded with a camcorder, and the time required to thin each 163 tree was measured to calculate the thinning costs.

165 To evaluate quality parameters, on each harvest date, a sample of 100 fruits was taken.

166 Several parameters were analysed: (i) the pulp firmness was measured by means of a

167 Magness-Taylor style penetrometer probe (Fruit Pressure Tester, FT-327, Facchini

168 SRL, Alfonsine, Italy) equipped with an 8-mm-diameter probe (section $50 \mathrm{~mm}^{2}$ ), (ii) the

169 total content of soluble solids in the fruits was determined from juice samples using a 
170 hand refractometer (Atago Pocket Pal-1, Atago Co. Ltd., Tokyo, Japan), (iii) the level of 171 acidity was obtained by neutralising $1.5 \mathrm{~mL}$ of the squeezed, spin-dried and filtered 172 juice with $0.1 \mathrm{~N} \mathrm{NaOH}$, using a digital $\mathrm{pH}$ meter (Crison $\mathrm{pH}$ Burette 24, Crison

173 Instruments S.A., Barcelona, Spain). The results were expressed in terms of the

174 dominant acid as grams of malic acid per litre ( $\mathrm{g}$ malic acid $\left.\mathrm{L}^{-1}\right)$.

176 The data were analysed using a one-way analysis of variance, and the mean difference 177 between treatments was separated by the least significant difference (Tukey HSD test) test at $\mathrm{P}<0.05$. The Statgraphics Plus 5.1 software was used to run the analysis.

180 The economic profit of the thinning treatments was calculated considering the yield $(\mathrm{kg}$ tree $^{-1}$ ) of fruits with diameters $>56 \mathrm{~mm}$ because this is the minimum size to be considered in the category "extra" according to CEE directive 3596/90, Ministerio de

183 Agricultura, Pesca y Alimentación, (1995). The three categories based on their 184 diameters were: over $67 \mathrm{~mm}, 61-67 \mathrm{~mm}$, and 56-61 mm. The price of the peaches $(€$ $185 \mathrm{~kg}^{-1}$ ) by categories (Table 1) was obtained from the wholesale weekly prices received 186 by producers in the field (personal communication). The thinning cost (€ tree ${ }^{-1}$ ) was subtracted from the production value $\left(€\right.$ tree $\left.^{-1}\right)$ to obtain the net margin.

The economic costs for the mechanical devices were calculated following ASAE D497.5 (2006) and ASAE EP496.3 (2006). The following parameters were used: a machine life of 5 years or $1200 \mathrm{~h}$, an annual usage of $240 \mathrm{~h}$, an interest rate of $7 \%$, a salvage value of $12 \%$ of the purchase price, storage at $0.75 \%$ of the purchase price and cumulative repair and maintenance costs at $82 \%$ of the purchase price. The hand-labour cost was $8.22 € \mathrm{~h}^{-1}$, including taxes. All prices were standard for the year 2010 .

Three economic scenarios were analysed: (i) fruits of all three categories have commercial value, (ii) only fruits of the 1 st to $2^{\text {nd }}$ categories have commercial value and (iii) only the fruits of the largest size category have commercial value.

\section{Results}

\section{3.1. Effect of thinning on distance between flowers or green fruits}

202 Scaffold length was similar in all treatments. The mean distance between flowers prior

203 to thinning was $2.3 \mathrm{~cm}$ (treatment 5, Table 2). Hand thinning produced the highest 
separation between fruits, $10.1 \mathrm{~cm}$. The mean distance between flowers thinned by the three mechanical devices (treatments 2, 3 and 4) did not differ significantly between them, ranging from 5.2 to $6.9 \mathrm{~cm}$.

207

\subsection{Thinning time and thinning efficiency}

209 The mechanical devices reduced the thinning time by $92 \%$ in 2009 and $86 \%$ in 2010

210 compared to hand thinning (Table 3). Within each year, there were no significant

211 differences between mechanical treatments; in 2009, the thinning time was 2.4-3.0 min

212 tree $^{-1}$, and in 2010 it was 4.1-5.8 min tree $^{-1}$. In 2010 thinning with the three devices used

213 more time than in 2009. The tree size was similar, but the operators were different, and

214 the use of these devices is strongly dependent on the operator skill.

215

216 In 2010, the thinning time was higher than in 2009 and, consequently, the fruit load was 217 lower (2.7 fruit $\mathrm{cm}^{-2}$ TCSA in 2010 and 4.8 fruits $\mathrm{cm}^{-2}$ TCSA in 2009). This correlation 218 was not obtained in the hand-thinning treatment, which gave a similar fruit load in both years (3.8 fruits $\mathrm{cm}^{-2}$ TCSA in 2009 and 3.1 fruits $\mathrm{cm}^{-2}$ TCSA in 2010).

221 On average for both years, mechanical thinning reduced by $48 \%$ the number of fruits

$222 \mathrm{~cm}^{-2}$ TCSA, while hand thinning diminished it by 53\%. In 2010, there were no

223 significant differences between the four thinning techniques. In 2009, thinning with

224 devices $\mathrm{A}$ and $\mathrm{C}$ resulted in a higher fruit load (5.6-4.9 fruit $\mathrm{cm}^{-2} \mathrm{TCSA}$ ).

225

\subsection{Optimizing crop load}

227

The more fruits per tree, the lower the average weight per fruit (Myers et al., 2002). Our experiments provided similar results; the highest fruit load (7.5-7.3 fruits $\mathrm{cm}^{-2}$ TCSA) and the lowest fruit size (98-108 $\left.\mathrm{g}_{\text {fruit }}{ }^{-1}\right)$ were obtained from unthinned trees (Table 3). load (no. fruit $\mathrm{cm}^{-2}$ TCSA) was performed on the data from the years 2009 and 2010, yielding a high correlation (Fig. 4). The best adjusting model was of the type:

$234 \quad y=1 /\left(a+b^{*} x^{2}\right)$

235 Where, $\mathbf{y}$ is the mean fruit size ( $\mathrm{g}$ fruit ${ }^{-1}$ ), and $\mathbf{x}$ is the fruit load (no. fruit $\mathrm{cm}^{-2}$ TCSA). 236 
237 Also, there was a high correlation between yield efficiency $\left(\mathrm{kg} \mathrm{cm}^{-2}\right.$ TCSA) and fruit

238 load (no. fruit $\mathrm{cm}^{-2}$ TCSA) in 2009 and 2010 (Fig. 5). The best adjusting model was of

239 the type:

$240 \quad \mathbf{y}=\exp (\mathbf{a}+\mathbf{b} / \mathbf{x})$

241 Where $\mathbf{y}$ is the mean fruit size $\left(\mathrm{kg} \mathrm{cm}^{-2} \mathrm{TCSA}\right)$ and $\mathbf{x}$ is the fruit load (no. fruit $\mathrm{cm}^{-2}$

242 TCSA).

243

244

3.4. Fruit per tree, yield and fruit size category

245

In 2009, unthinned trees produced 1115 peaches per tree. Treatments 1 and 3 had lower fruit densities of 534 and 512 fruits per tree, respectively (Table 4). In treatments 2 and 4, significantly more fruits were harvested: 656 and 609, respectively. However, these differences in fruit load were not significantly reflected in the yield by tree $\left(\mathrm{kg}_{\mathrm{g}}\right.$ tree $\left.{ }^{-1}\right)$, with the only exception that unthinned trees that yielded more than all the other treatments. The percentage of fruits in the top size category $(>76 \mathrm{~mm})$ was similar for all the treatments (46\% on average), with the exception of unthinned treatment $(15 \%)$. The combined weight of the fruits in this category was also higher in the thinned trees (on average, $48.3 \mathrm{~kg}$ tree $^{-1}$ ) than in the unthinned $\left(25.1 \mathrm{~kg} \mathrm{tree}^{-1}\right)$.

In 2009, the thinned trees had $52 \%$ as many fruits as the un-thinned trees. In 2010, this percentage decreased to $41 \%$; therefore, the thinning intensity was higher in 2010 than in 2009. In 2010, there were no significant differences among treatments 1 through 4 in either the number of fruits per tree or the yield.

260 In summary, in both years, the results obtained in treatments 1 through 4 (mechanical devices and control) were similar in terms of the fruit load (597 fruit tree ${ }^{-1}$ ) and yield $\left(77 \mathrm{~kg} \mathrm{tree}^{-1}\right)$ as well as the percentage of fruits in the top two categories (81\% of fruits $>61 \mathrm{~mm}$ in diameter). The unthinned trees produced more fruits (1069 fruit tree ${ }^{-1}$ ) and a greater yield $\left(109 \mathrm{~kg} \mathrm{tree}^{-1}\right.$ ) but a lower percentage of bigger fruits (only $50 \%$ of fruits $>61 \mathrm{~mm}$ in diameter). In terms of the yield of the superior categories of fruits (>61 $\mathrm{mm}$ ), the differences were less notable: $68.35 \mathrm{~kg}$ tree $^{-1}$ on average for treatments 1 to 4 versus $67.1 \mathrm{~kg}$ tree ${ }^{-1}$ for treatment 5 .

\subsection{Physical-chemical properties of fruits}


The fruit quality was evaluated at each harvest date. The average firmness was similar in both years, $36.08 \mathrm{~N}$ and $36.09 \mathrm{~N}$, in 2009 and 2010 respectively. There were no significant differences in firmness between harvesting data in each year. The acidity increased with harvest date both years, but the differences were not significant, $5.57 \mathrm{~g}$ malic acid L-1 in 2009 and $5.51 \mathrm{~g}$ malic acid L-1 in 2010). The soluble solids content was $9.65^{\circ}$ Brix in 2009 and $10.96^{\circ}$ Brix in 2010. In both years, soluble solids content was always higher on the first harvest date, although the differences were significant only in 2009.

The acid increase and the sugars decrease in the former harvesting dates can be explained by the selective manual harvesting. In the first dates, workers take only the biggest and more colored fruits, meanwhile in the last, they take all the remnant fruits of the tree, with independence of its maturity stage.

3.6. Economic value by marketable fruits, cost of thinning and net value of peach fruits

286 Hand thinning was the technique with the lowest hourly cost $\left(8.22 € \mathrm{~h}^{-1}\right)$ (Table 5).

287 Mechanical techniques had a higher hourly cost due mainly to the purchase price of the 288 device. Thinning with mechanical devices took $9.93 € \mathrm{~h}^{-1}, 9.41 € \mathrm{~h}^{-1}$ and $11.5 € \mathrm{~h}^{-1}$ for

289 devices A, B and C, respectively. Despite these higher hourly costs, the great time 290 savings of $91-93 \%$ in 2009 and $83-88 \%$ in 2010 with the mechanical devices (Table 3) 291 lowered the total thinning cost with mechanical devices to $90 \%$ and $82 \%$ of the cost of 292 thinning by hand in 2009 and 2010, respectively (Table 6). The thinning costs were 4.8

$293 €$ tree $^{-1}$ for hand thinning compared to $0.7 €$ tree $^{-1}$ on average for the mechanical 294 treatments.

There were no significant differences among the treatments in the economic value of the peach crops in both years (Table 6). Although by categories, treatments 1 through 4

298 fetched more money $\left(€\right.$ tree $\left.^{-1}\right)$ in the two superior fruit size categories, and treatment 5

299 (not thinned) obtained a higher value in the inferior size category (56-60 mm).

301 The net value ( $€$ tree $^{-1}$ ) was similar for all the treatments (Table 6), but, sometimes, as in

302 the years with an excess of fruit on the markets, farmers have difficulty selling the

303 inferior categories of fruits. To analyze this possibility, three hypothesis were studied: 
304 (i) the three categories are all accepted by the market, (ii) only the two top categories

305 are accepted and (iii) only the fruits of the first category can be sold (Fig. 6). In the first

306 case (i), all the treatments, including not thinning, yield a similar net value. However, in

307 scenarios (ii) and (iii), not thinning had the lowest net value, and there were no clear

308 differences between the other treatments.

309

310 4. Discussion

\section{4.1. Hand thinning vs. not thinning}

312 Hand thinning reduced the number of fruits $50 \%$ and yield $29 \%$ on average for both

313 years. In the other hand, fruit size increased $56 \%$ and also the proportion of top size

314 fruits. As farmers in Spain, usually do not produce peaches exclusively for processing,

315 if not that they try to sell part or the total production for the fresh market, they thin all

316 the trees as for fresh. But this practice, can lead to an over-thinning and so, to a minor

317 profitability.

318 The total net value $\left(€\right.$ tree $\left.^{-1}\right)$ depends on the yield and price of fruits within the different

319 size categories. Usually, farmers receive higher prices for the higher categories, and

320 these higher prices compensate for the total yield reduction. In 2009 and 2010, yields

321 were reduced $25 \%$ and $32 \%$ by hand thinning compared to not thinning, but there were

322 no significant differences in the total net value (Table 6). Hand thinning had a cost of

3234.8 and $4.7 €$ tree $^{-1}$ (around $10 \%$ of the gross value) that can reduce the net value of

324 thinned peaches to below the value of peaches from unthinned trees, but the differences

325 are small $\left(41.39 €\right.$ tree $^{-1}$ versus $47.81 €$ tree $^{-1}$ in 2009 and 46.32 tree $^{-1}$ versus $47.73 €$

326 tree $e^{-1}$ in 2010). On the other hand, hand thinning makes peach marketing easy, even in

327 the more unfavourable scenarios, like when only the higher size categories are

328 marketable. The net economic values for the top category of fruits (>67 mm) was 13

329 and $7 €$ tree $^{-1}$ in unthinned trees versus 27 and $24 €$ tree $^{-1}$ in hand-thinned trees in 2009

330 and 2010, respectively (Fig. 6).

\subsection{Mechanical thinning vs. hand thinning}

333 In 2010, a similar number of fruits were harvested from mechanically thinned trees (332

334 to 461 fruit tre ${ }^{-1}$ ) as in hand-thinned trees (440 fruit tree ${ }^{-1}$ ) (Table 4). However, when

335 the distance between flowers was measured immediately after thinning, the distance was

$33610.1 \mathrm{~cm}$ in hand-thinned trees and 5.2-6.9 $\mathrm{cm}$ in mechanically-thinned trees (Table 2).

337 Thus, more fruits would be expected at harvest from the mechanical treatments. A 
possible explanation for this discordance is that some flowers were damaged by the mechanical thinning operation, and later, after measuring the distances, they fell. In

340 future studies, the distance measurement must be done some weeks after thinning to avoid this problem.

In 2010, there were no significant differences in fruit load, yield efficiency, mean fruit size, fruit per tree, yield per tree and fruit size category between the hand-thinning and mechanical-thinning treatments (Table 3 and Table 4). In 2009, device B (treatment 3) also gave similar results to hand thinning, but the other two devices showed some differences from hand thinning.

In both years, there were no significant differences in the net value of peaches thinned by hand or by machine (Table 6), nevertheless, hand thinning took 389 and $380 \mathrm{~h} \mathrm{ha}^{-1}$ versus 31-55 h ha-1 for mechanical thinning in 2009 and 2010, respectively. Thus, mechanical thinning increased the working capacity of the operators by 8.9 times, and this provides a great advantage for farmers who need to have to their crops thinned in a short period of time (40-50 days) and have difficulties finding enough manpower. Perhaps, this was the main advantage of the mechanical thinning because there were no significant differences between the net value $\left(€\right.$ tree $\left.^{-1}\right)$ resulting from the manual and mechanical thinning treatments (Table 6).

\subsection{Strategies for optimizing thinning intensity with hand-held thinners}

At thinning time, farmers must take a decision about the final use of its peaches, fresh or processing, because it is related with the desired fruit size. On the other hand, the relationship between yield and fruit size with fruit load can be calculated by regression analysis as showed in figures 4 and 5 , so that the farmer will have an idea about the optimum fruit load. Obviously, regression coefficients must be obtained for each crop and its particular conditions.

367 If the farmer decides to do mechanical thinning with portable devices, a system to control thinning intensity with these devices is to measure the time used to thin each tree, since the thinning intensity is highly dependent on the thinning time (Table 3). The 
371 the devices used (treatments 2-4) in 2009 and 2010 shows a high correlation according

372 to the model:

$$
\mathbf{y}=1064.63-277.77 * \operatorname{sqrt}(\mathbf{x})
$$

374 Where $\mathbf{y}$ is the number of fruits tree ${ }^{-1}$ and $\mathbf{x}$ is the time of thinning (min tree ${ }^{-1}$ ), with a $\mathrm{R}^{2}$ 375 adjusted $=78 \%$.

376

377 This correlation was not obtained for the hand-thinning treatments, so the use of

378 mechanical devices improved the productivity of thinning.

380 The main advantage of the hand-held tested thinners, compared with the tractor driven 381 ones, is that the can be used in almost all type of tree conduction, it is not necessary to 382 introduce pruning changes, although short scaffolds will facilitate thinning.

384 After 5 years of thinning with these equipments, no damages have been noticed in the 385 limbs or in the bark of the young branches. No changes have been appreciated in the 386 return bloom after mechanical thinning.

\section{Conclusions}

389 Thinning, either by hand or mechanically, reduced the yield per tree by $30 \%$, but 390 increased the yield of fruits in the highest size category (>67 mm). Moreover, $50 \%$ of 391 the fruits from thinned trees were within the highest size category versus $13 \%$ of fruits 392 from unthinned trees.

394 No significant differences were found between the three mechanical thinners tested in terms of the thinning time or the number of fruits per $\mathrm{cm}^{2}$ TCSA.

397 In both years, the net economic value of the total yield and also the yield per size

398 category was similar for manual and mechanical thinning, but the thinning time was 385 $399 \mathrm{~h} \mathrm{ha}^{-1}$ with hand thinning versus $42 \mathrm{~h} \mathrm{ha}^{-1}$ with mechanical thinning.

400

401 Mechanical thinning was $86 \%$ cheaper than hand thinning. The thinning cost by tree ( $€$

402 tree $^{-1}$ ) accounted for $10 \%$ of the gross value of the peaches for hand thinning and $2 \%$ for 403 mechanical thinning. 
405 There is a good correlation between the mechanical thinning time (min tree ${ }^{-1}$ ) and the

406 thinning intensity (no. fruits tree ${ }^{-1}$ ). As the thinning time is easy to measure, it is a

407 parameter that can be used by workers to govern thinning intensity with hand-held

408 thinners.

409

\section{Acknowledgements}

411 This research was funded by the Consejería de Agricultura de la Región de Murcia,

412 Spain. The authors thank Eng. Regino Aragón (IMIDA) and Marín Giménez Hermanos

413 S.A. (Caravaca, Spain) for their support.

414

415 References

416 ASAE D497.5, 2006. Agricultural machinery management data. ASABE Standards (2), 417 391-398.

418 ASAE EP496.3, 2006. Agricultural machinery management. ASABE Standards (2), $419 \quad 385-390$.

420 Baugher, T.A., Ellis, K., Remcheck, J., Lesser, K., Schupp, J., Winzeler, E., Reichard

421 K., 2010. Mechanical string thinner reduces crop load at variable stages of bloom

422 development of peach and nectarine trees. HorScience 45(9), 1327-1331.

423 Byers, R.E., Lyons, C.G., 1985. Peach flower thinning and possible sites of action of

424 desiccating chemicals. J. Amer. Soc. Hort. Sci. 110, 662-667.

425 Costa, G., Vizzotto, G., 2000. Fruit thinning of peach trees. Plant Growth Regul. 31, 426 113-119.

427 Garcia, J., 2007. Evaluación Económica y eficiencia del agua de riego en frutales de

428 regadío [In Spanish], first ed. Consejería de Agricultura y Agua, Murcia.

429 Martin, B., Torregrosa, A., Aragon, R., Garcia Bruton, J., 2009. Dispositivo mecánico

430 portátil para el aclareo de flores y frutos recién cuajados en árboles y arbustos [In

431 Spanish]. Spanish Patent No. ES200901448.

432 Martin, B., Torregrosa, A., Garcia Brunton, J., 2010. Post-bloom thinning of peaches

433 for canning with hand-held mechanical devices. Sci. Hortic. 125(4), 658-665. DOI:

$434 \quad \underline{10.1016 / j . s c i e n t a .2010 .05 .025 .}$

435 Marini, R. P., Sowers, D.L., 1994. Peach fruit weight is influenced by crop density and

436 fruiting shoot length but not position on the shoot. J. Amer. Soc. Hort. Sci. 119(2), 180 $437 \quad 184$. 
438 Myers, S.C., Savelle, A.T., Tustin, D.S., Byers, R.E., 2002. Partial flower thinning

439 increases shoot growth, fruit size, and subsequent flower formation of peach.

440 HortScience 37, 647-650.

441 Ministerio de Agricultura, Pesca y Alimentación, 1995. Normas de calidad de frutas y

442 hortalizas [In Spanish]. Ministerio de Agricultura, Pesca y Alimentación Secretaria

443 General de Alimentación, Madrid, Spain.

444 Miranda, C., Royo, J.B., 2002. Fruit distribution and early thinning intensity influence

445 fruit quality and productivity of peach and nectarine trees. J. Amer. Soc. Hort. Sci.

446 127(6), 892-900.

447 Miranda, C., Royo, J.B., 2003. A statistical model to estimate potential yields in peach

448 before bloom. J. Amer. Soc. Hort. Sci. 128(3), 297-301.

449 Rosa, U.A., Cheetancheri, K.G., Gliever, C.J., Lee, S.H., Thompson, J., Slaughter, D.C.,

450 2008. An electro-mechanical limb shaker for fruit thinning. Comput. Electron. Agric.

$451 \quad 61,213-221$.

452 Schupp, J.J., Baugher, T. A., Miller, S.S., Harsh, R.M., Lesser, K.M., 2008. Mechanical

453 thinning of peach and apple trees reduces labor input and increases fruit size.

454 HorTechnolgy 18 (4), 660-670.

455 Scott, R., Rasmussem, J.M., 1990. Peach thinning optimization model. Acta Hortic.

$456276,247-255$.

457 Torregrosa, A., Martin, B., Garcia Brunton, J., Bernad, J.J., 2008. Mechanical

458 harvesting of processed peaches. Appl. Eng. Agr. 24 (6), 723-729. 